\title{
EPITHELIAL CELL DEATH IN THE OIL-INDUCED DECIDUAL REACTION OF THE PSEUDOPREGNANT MOUSE: AN ULTRASTRUCTURAL STUDY
}

\author{
J. R. HINGHLIFFE AND A. M. EL-SHERSHABY* \\ Zoology Department, University College of Wales, \\ Penglais, Aberystreyth SY23 3DA, Dyfed, Wales
}

(Received 3rd February 1975)

\begin{abstract}
Summary. Arachis oil instilled into the uterus of sensitized mice was localized mesometrially or, more commonly, antimesometrially, suggesting that the uterus is polarized in its capacity to respond since implantation chambers only form antimesometrially. Epithelial breakdown occurred only within the 'implantation chamber', but cell death took place more rapidly than in normal pregnancy and was complete at only 5 to $9 \mathrm{hr}$ after the Pontamine Blue reaction. Between 19 and $43 \mathrm{hr}$ after oil instillation, the antimesometrial epithelial cells lost contact with each other and initially were characterized by distended rough endoplasmic reticulum and Golgi body, lipid droplet accumulation and ribosome segregation. At a later stage of deterioration, epithelial cell contents were scattered into the uterine lumen where polymorphonuclear leucocytes and monocytes were also found, probably involved in ingesting the cellular debris. There was no evidence of increased size of lysosomal dense bodies or of the formation of autophagosomes in dying epithelial cells; suggesting that the mechanism of epithelial death in the oil-induced reaction is not identical to that of normal pregnancy.
\end{abstract}

\section{INTRODUGTION}

It is now well established that the mouse uterus has the capacity for the formation of an 'implantation chamber' (Finn, 1971) which may be triggered either by the blastocyst in normal pregnancy or by an artificial stimulus such as arachis oil (Finn \& Keen, 1963) instilled in a sensitized pseudopregnant uterus. Such an implantation chamber is formed by two major processes; the formation of decidual cells, followed by the deterioration and death of the antimesometrial epithelial cells as described at the light microscope level by Finn \& Hinchliffe $(1964,1965)$. The fact that epithelial death occurs without the presence of a blastocyst suggests that death is the result of autolytic changes in both normal and oil-induced reactions and ultrastructural observations of

\footnotetext{
* Present address: Department of Zoology, Faculty of Science, University of Assiout, Assiout, A.R. Egypt.
} 
autophagosome formation during epithelial death in normal pregnancy confirm the epithelial autolysis theory (El-Shershaby \& Hinchliffe, 1975). The present study examines ultrastructurally the process of epithelial cell death during the oil-induced decidual reaction and contrasts it with the different process in normal pregnancy. In addition, the localization of the instilled arachis oil is examined with a view to providing evidence relating to the triggering of the decidual reaction. A more detailed account of the process of oil-induced epithelial deterioration described here is given by El-Shershaby (1974).

\section{MATERIALS AND METHODS}

Random-bred albino mice were ovariectomized through flank incisions under Avertin anaesthesia. Uterine sensitivity to a decidual stimulus was induced by exogenous hormone administration following the procedure of Finn \& Martin (1972). After ovariectomy, females were rested for 2 days, then primed for 3 days with $0 \cdot 1 \mu \mathrm{g}$ oestradiol-17 $\beta$. After a further 3 days $500 \mu \mathrm{g}$ progesterone $+0.1 \mu \mathrm{g}$ oestradiol were administered for 3 to 5 days, the first day of treatment being called Day 1 . Hormones were administered subcutaneously in $0.05 \mathrm{ml}$ arachis oil at about 10.00 hours. The decidual stimulus consisted of the instillation of $0.01 \mathrm{ml}$ arachis oil under Avertin anaesthesia into the left horn of the uterus through the uterotubal junction on Day 3 at 16.00 hours, the time of maximum uterine sensitivity (Finn \& Martin, 1969).

Successful initiation of the decidual reaction was inferred from the appearance of blue coloration in the left uterine horn, following intravenous injection of $0.25 \mathrm{ml}$ Pontamine Sky Blue (Psychoyos, 1961). Positive staining is first found 12 to $14 \mathrm{hr}$ after arachis oil instillation (Finn, 1971). Uteri were fixed at 14, $19,24,29,39$ or $43 \mathrm{hr}$ after oil instillation. The whole left uterine horn was dissected out into cold $\left(0\right.$ to $\left.4^{\circ} \mathrm{C}\right)$ glutaraldehyde for $\frac{1}{2} \mathrm{hr}$, and the blue sites were then cut into small blocks (side of 1 to $1.5 \mathrm{~mm}$ ) and fixed for a further $2 \frac{1}{2} \mathrm{hr}$ in $4 \%$ glutaraldehyde. The pieces of uterus were post-fixed in $1 \%$ osmium tetroxide for $2 \mathrm{hr}$, then washed in cacodylate buffer and dehydrated and embedded in Araldite/epon mixture or in Araldite alone. Thin ( $1 \mu \mathrm{m})$ light microscope sections stained in hot $0.2 \%$ toluidine blue, and ultrathin (silver) sections stained with $5 \%$ uranyl acetate and lead citrate, were prepared and examined.

\section{RESULTS}

\section{General observations}

Oil droplets fixed by the osmium treatment, and often containing cellular debris, were found in mesometrial and central positions in the uterus, but they were more common in the antimesometrial position where they formed at the centre of the implantation chamber (Pl. 1, Figs 1 and 2). The arachis oil droplets frequently penetrated into the stromal area antimesometrially, and were also found within epithelial cells.

Epithelial degeneration was confined to the antimesometrial position and to 
the centre of the Pontamine Blue-positive pieces of uterus. Sections taken away from the centre of a Pontamine Blue-positive implantation chamber, or from a Pontamine Blue-negative piece of uterus, showed no epithelial degeneration. Epithelial breakdown after oil instillation occurred more rapidly than in normal pregnancy, the oil-induced breakdown being complete 5 to $9 \mathrm{hr}$ after the Pontamine Blue reaction.

Between 19 and $43 \mathrm{hr}$ after oil instillation, the average height of the epithelial cells in the antimesometrial half of the uterus was substantially less (Table 1) than that of mesometrial cells, as in normal implantation.

Polymorphonuclear leucocytes and monocytes were also present at this time in large numbers both between epithelial cells (Pl. 1, Fig. 3) and in the lumen, adjacent to dying epithelial cells and cellular debris.

Table 1. The effect of instillation of arachis oil on the mean height of epithelial cells in the sensitized uterus of the mouse

\begin{tabular}{ccc}
\hline $\begin{array}{c}\text { Time after oil } \\
\text { instillation }(h r)\end{array}$ & $\begin{array}{c}\text { Mesometrial } \\
\text { cells }(\mu \mathrm{m})\end{array}$ & $\begin{array}{c}\text { Antimesometrial } \\
\text { cells }(\mu \mathrm{m})\end{array}$ \\
\hline 14 & $26 \cdot 6$ & $27 \cdot 3$ \\
19 & $22 \cdot 8$ & $16 \cdot 4$ \\
24 & $19 \cdot 0$ & $13 \cdot 7$ \\
29 & $21 \cdot 7$ & $13 \cdot 5$ \\
39 & $12 \cdot 5$ & $10 \cdot 2$ \\
\hline
\end{tabular}

Each value represents the mean height of 144 cells.

\section{Death of antimesometrial uterine epithelial cells}

After oil instillation the uterine epithelium remained intact at $14 \mathrm{hr}$ in mesometrial and antimesometrial positions, and also between 19 and $43 \mathrm{hr}$ mesometrially. It consisted of tall columnar cells, which were similar ultrastructurally to the uterine epithelial cells at $95 \mathrm{hr}$ in normal implantation (El-Shershaby \& Hinchliffe, 1975). Dense lysosomal bodies ('residual bodies') were present in the apical cytoplasm (PI. 1, Fig. 1).

Single dead epithelial cells were found in considerable numbers in the mesometrial (14 to $43 \mathrm{hr}$ ) and antimesometrial epithelium up to the time of general epithelial breakdown (P1. 1, Fig. 1), and were also present in the lumen. Ultrastructurally they showed chromatopyknosis and cytoplasmic vacuolation, and were similar to the single dead cells found adjacent to the implanting blastocyst at 95 to $116 \mathrm{hr}$ described by El-Shershaby \& Hinchliffe $(1974,1975)$.

General antimesometrial cell death was a separate process from the death of single cells just described, and incipient antimesometrial breakdown was first recognizable $19 \mathrm{hr}$ after oil instillation. The basement membrane became thickened with prominent bundles of collagen fibres and was thus similar to the thickened basement membrane of the implantation chamber in normal pregnancy (Smith \& Wilson, 1974a). Many of the epithelial cells lost contact with the basement membrane, and at the same time lost their polarization and 
became rounded (PI. 2, Fig. 4; PI. 3, Fig. 7). Chromatin accumulated at the nuclear margin, the cytoplasm was vacuolated and contained distended rough endoplasmic reticulum and Golgi body, many lipid droplets and segregated ribosomes (Pl. 2, Fig. 4; Pl. 3, Figs 6 and 7). An unusual dense mass was sometimes observed in the nucleus (Pl. 3, Fig. 7). Lysosomal dense bodies appeared to be unchanged in size and number compared with normal epithelial cells, and there was no evidence of autophagosomes.

A later stage of breakdown consisting of almost completely disintegrated dead epithelial cells was found, at 24 to $39 \mathrm{hr}$ (Pl. 2, Fig. 5). Cytoplasmic ground substance and cellular organelles were present in the uterine lumen, and chromatopyknotic and sometimes fragmented nuclei, lipid droplets and residual bodies could also be identified. Such regions of deterioration contained numerous polymorphonuclear leucocytes and macrophages presumably engaged in phagocytic ingestion of the cellular debris (Pl. 2, Fig. 5).

The process of epithelial breakdown after oil induction showed more variation between and within animals than in normal pregnancy: the breakdown was faster in some individuals than others (compare Pl. 2, Fig. 4 with Pl. 3, Fig. 7), while the response within a single 'implantation chamber' was variable in that areas of necrosis and of intact cells were found in close proximity. While in

\section{EXPLANATIONS OF PLATES}

Sections through the uterine epithelium of the mouse after the instillation of arachis oil as a decidualizing stimulus. Abbreviations: ch, chromatin condensation; db, dense body; dec, single dead epithelial cell; deb, epithelial debris; g, nuclear gap; li, lipid; o, arachis oil; $p$, polymorphonuclear leucocytes; s, stroma; ver, vacuolated endoplasmic reticulum.

\section{PLATE 1}

Figs 1 and 2. Light micrographs of the mesometrial epithelium (Fig. 1) and antimesometrial epithelium (Fig. 2) of an 'implantation chamber' $24 \mathrm{hr}$ after instillation of oil. Note the single dead epithelial cells in the viable mesometrial epithelium (ep), and the general epithelial breakdown (geb) antimesometrially.

Fig. 3. Infiltration of mesometrial epithelium at $19 \mathrm{hr}$ after instillation of oil by three polymorphonuclear leucocytes and a monocyte $(\mathrm{m})$. Note dense bodies ('residual bodies') in the apical cytoplasm of the viable epithelial cells.

\section{PLATE 2}

Fig. 4. Loose deteriorating epithelial cells from an 'implantation chamber' at $19 \mathrm{hr}$ after instillation of oil. The epithelial cells are rounded and have lost their polarization, and the basement membrane (bm) has an accumulation of collagen (c). The cells show chromatopyknosis, lipid accumulation, and vacuolation (v) of the cytoplasm, but the dense bodies remain unchanged in size.

FIG. 5. Complete deterioration of epithelium in an 'implantation chamber' $24 \mathrm{hr}$ after oil instillation. Cytoplasmic ground substance, lipid droplets and cellular organelles are scattered into the uterine lumen: the cellular structure of the epithelium is completely lost. Polymorphonuclear leucocytes and macrophages (ma) are frequently found in the debris.

PLATE 3

Fig. 6. Detail of deteriorating epithelial cell from the 'implantation chamber' $39 \mathrm{hr}$ after oil instillation. Note chromatin condensation at the nuclear margin, lipid accumulation, ribosomal segregation (rs) and distended rough endoplasmic reticulum and Golgi body (dG).

FIG. 7. Deteriorating epithelium from the 'implantation chamber' $39 \mathrm{hr}$ after oil instillation. In addition to the features already described in Fig. 6, note the rounded nature of the cells, the gap between nuclear membranes and the unusual dense masses $(\mathrm{dm})$ in the nuclei. 
PLATE 1

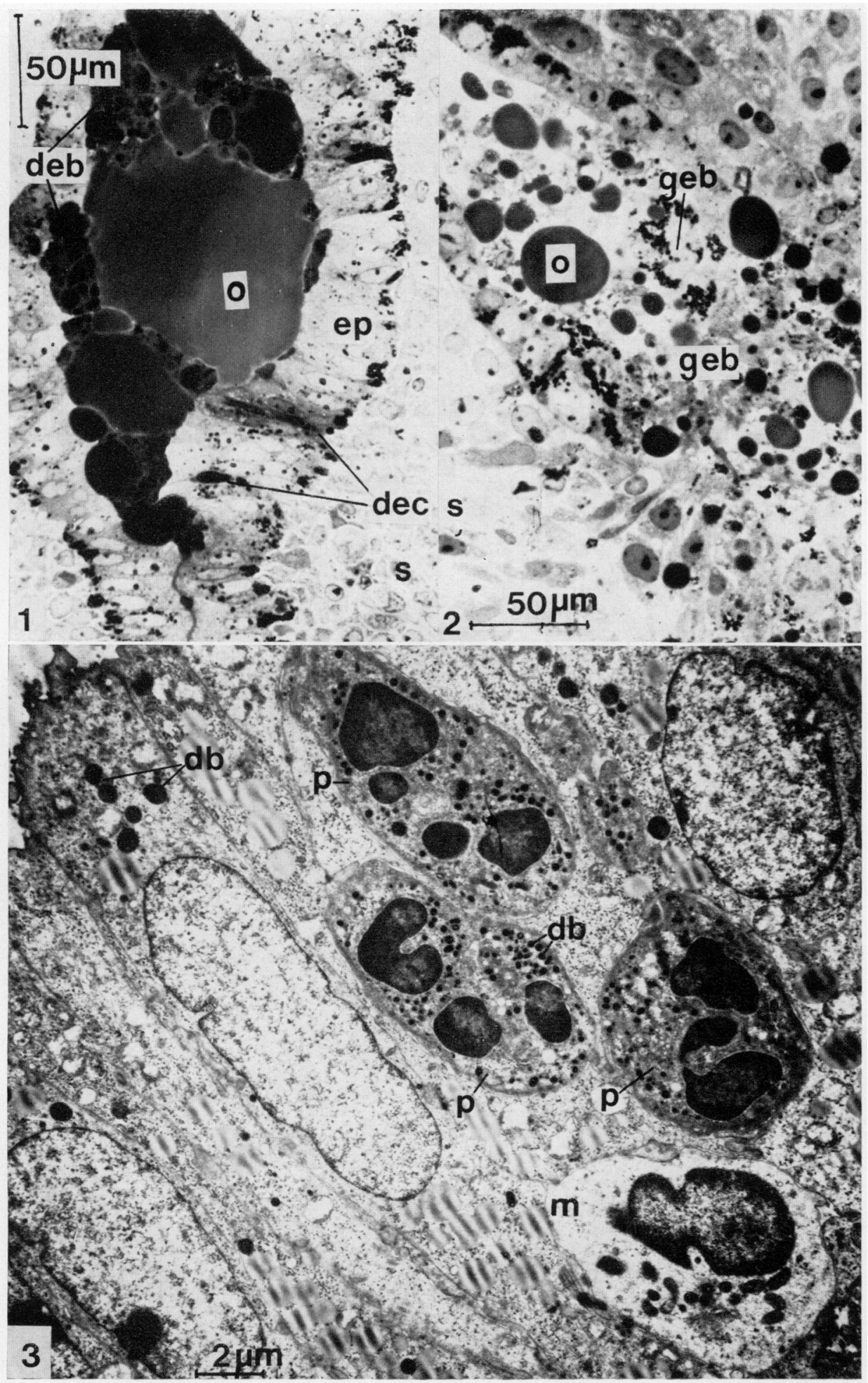

(Facing p. 466) 


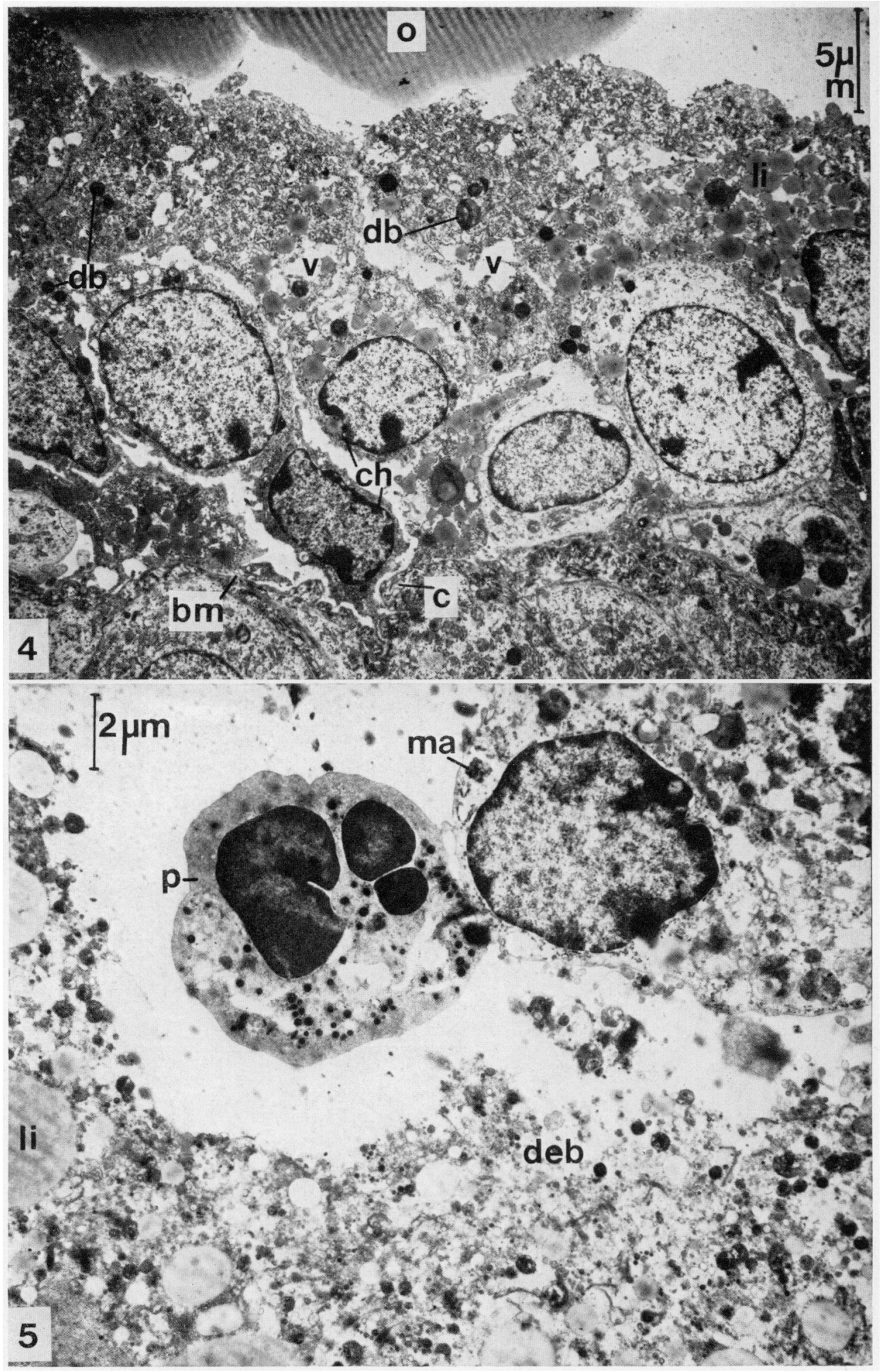




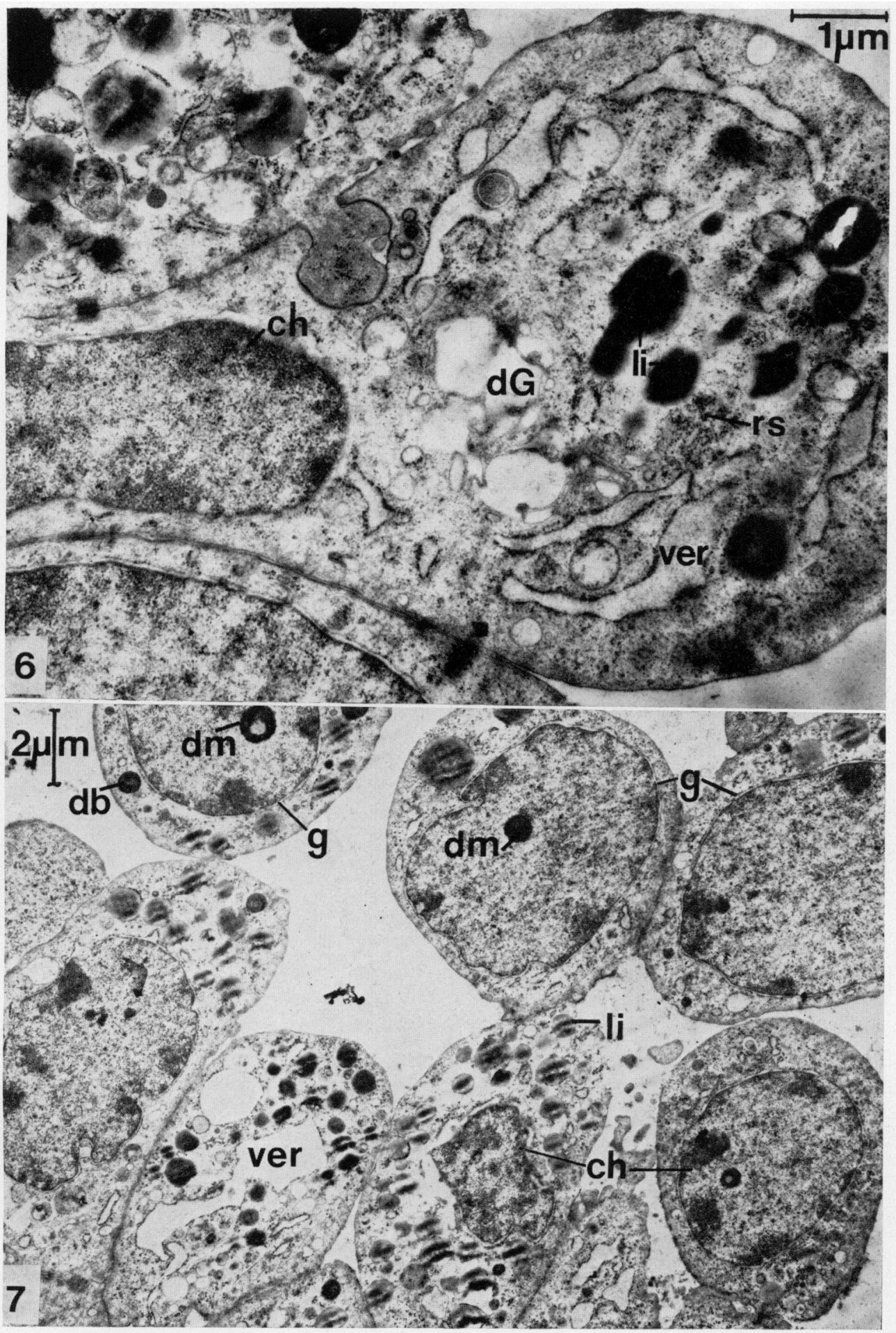


general the area of epithelial necrosis and the stage of necrosis reached increased during the period 19 to $43 \mathrm{hr}$ after oil instillation, patches of intact cells were still present at $43 \mathrm{hr}$.

\section{DISCUSSION}

The finding that arachis oil may be located mesometrially as well as antimesometrially rules out the possibility that the artificially induced decidual reaction is solely the result of a uterine mechanism which 'places' the oil antimesometrially. The result emphasizes instead that the uterus is polarized in its capacity for response to instilled oil, only the antimesometrial part having the capacity for positive response. The partial contribution of a 'placing mechanism' cannot be completely ruled out, however, since arachis oil is observed more commonly in the antimesometrial position, a finding in line with the antimesometrial positioning of Diakon beads (McLaren, 1968) or tumour cells (Wilson, 1963) in a sensitive uterus.

The fact that antimesometrial epithelial breakdown in the implantation chamber can occur without the presence of a blastocyst has led previous workers to emphasize that the breakdown is due to an autolytic process inherent in the decidual reaction rather than to trophoblast activity (Krehbiel, 1937; Finn \& Hinchliffe, 1964; Finn, 1971). The evidence presented here, however, indicates that the oil-induced process of cell death, as examined ultrastructurally, is not identical to that in normal pregnancy. Such ultrastructural features as chromatopyknosis, lipid droplet accumulation and swelling of the endoplasmic reticulum and Golgi body are also found in normal pregnancy, but comparison of cell death in the two situations shows that there is no evidence of any increase in size of lysosomal dense residual bodies or of the appearance of autophagosomes ('cytosegrosomes') after oil instillation. Enlarged lysosomal dense bodies and the appearance of autophagosomes are characteristic of epithelial cell death in normal pregnancy in particular (El-Shershaby \& Hinchliffe, 1975), and of epithelial cell death in general (Ericsson, 1969). While possible differences in hormonal background should be borne in mind, one reason for this difference may be the more rapid process of cell death after the initiation of the artificial implantation reaction as compared with that in normal pregnancy. Deterioration is complete $24 \mathrm{hr}$ after the Pontamine Blue reaction in normal pregnancy (El-Shershaby \& Hinchliffe, 1975), as compared with only 5 to $9 \mathrm{hr}$ in the oilinduced reaction. Since the action of the oil is so rapid, it is suggested that antimesometrial epithelial cell death may be hastened by a direct deleterious effect of oil on cells which are beginning to deteriorate as part of the previously initiated process of formation of the implantation chamber. The oil does not directly kill epithelial cells in other areas of the uterus, however, and it is not being suggested that the initiation of the decidual reaction is by a traumatic action of the oil.

A further difference from normal pregnancy is that, beginning at $19 \mathrm{hr}$ after oil instillation, areas of epithelial deterioration are characterized by massive infiltration of polymorphonuclear leucocytes, monocytes and macrophages through the epithelium into the lumen. In normal pregnancy, polymorpho- 
nuclear leucocytes appear in smaller numbers in deteriorating epithelium, but they do not enter the lumen (Smith \& Wilson, 1974b). These scavenging cells in the oil induced-reaction presumably play the role of the trophoblast cells in normal pregnancy in ingesting and digesting the deteriorating epithelium.

While previous studies (Finn \& Hinchliffe, 1964) have emphasized similarities in the morphogenesis of the 'implantation chamber' in normal pregnancy and in the oil-induced reaction, the present detailed analysis at the ultrastructural level indicates that there are differences in the timing and mechanism of epithelial cell death. It may be that these deviations in the artificial response are due to the absence of a precise controlling mechanism provided by the blastocyst.

\section{AGKNOWLEDGMENT}

The authors would like to thank Dr Colin Finn for his assistance in carrying out the ovariectomy, exogenous hormone administration and oil instillation.

\section{REFERENCES}

EL-Shershaby, A.M. (1974) Cytological studies on cell death in blastocyst and uterine epithelium in relation to implantation in the mouse. Ph.D. thesis, University College of Wales, Aberystwyth.

EL-Shershaby, A.M. \& Hinchliffe, J.R. (1974) Cell redundancy in the zona-intact preimplantation mouse blastocyst: a light and electron microscope study of dead cells and their fate. $\mathcal{F}$. Embryol. exp. Morph. 31, 643-654.

El-Shershaby, A.M. \& Hinchliffe, J.R. (1975) Epithelial autolysis during implantation of the mouse blastocyst: an ultrastructural study. F. Embryol. exp. Morph. 33B, (in press).

ERIccson, J.L.E. (1969) Mechanism of cellular autophagy. In Lysosomes in Biology and Pathology, vol. II, pp. 345-394. Eds J. T. Dingle \& H. B. Fell. North Holland, Amsterdam.

Fins, C.A. (1971) The biology of decidual cells. Adv. Reprod. Physiol. 5, 1-26.

FinN, C.A. \& Hinchliffe, J.R. (1964) The reaction of the mouse uterus during implantation and deciduoma formation as demonstrated by changes in the distribution of alkaline phosphatase. 7. Reprod. Fert. 8, 331-338.

FinN, C.A. \& Hinchliffe, J.R. (1965) Histological and histochemical analysis of the formation of implantation chambers in the mouse uterus. F. Reprod. Fert. 9, 301-309.

Fins, C.A. \& KEEN, P.M. (1963) The induction of deciduomata in the rat. F. Embryol. exp. Morph. 11, $673-682$.

Finn, G.A. \& Martin, L. (1969) Hormone secretion during early pregnancy in the mouse. F. Endocr. $45,57-65$.

FinN, C.A. \& MARTin, L. (1972) Temporary interruption of the morphogenesis of deciduomata in the mouse uterus by actinomycin D. 7. Reprod. Fert. 31, 353-358.

KREHBIEL, R.H. (1937) Cytological studies of the decidual reaction in the rat during pregnancy and in the production of deciduomata. Physiol. Zool. 10, 212-233.

McLaren, A. (1968) Can beads stimulate a decidual response in the mouse uterus? 7. Reprod. Fert. $15,313-315$.

Psychoyos, A. (1961) Perméabilité capillaire et décidualization uterine. C. r. hebd. Séanc. Acad. Sci., Paris 252, 1515-1517.

Sмrth, A.F. \& Wilson, I.B. (1974a) Cell interaction at the maternal-embryonic interface during implantation in the mouse. Cell Tiss. Res. 152, 525-542.

Smith, A.F. \& Wirson, I.B. (1974b) Leucocytes in the luminal epithelium of the mouse uterus at implantation. F. Reprod. Fert. 38, 307-310.

Wruson, I.B. (1963) A tumour tissue analogue of the implanting mouse embryo. Proc. zool. Soc. Lond. 141, $137-151$. 